\title{
Technological aided assessment of the acutely ill patient - The case of postoperative complications
}

Haahr-Raunkjær, C.; Meyhoff, C. S.; Sørensen, Helge Bjarup Dissing; Olsen, Rasmus Munch; Aasvang, E. K.

\author{
Published in: \\ European Journal of Internal Medicine
}

Link to article, DOI:

10.1016/j.ejim.2017.09.031

Publication date:

2017

Document Version

Peer reviewed version

Link back to DTU Orbit

Citation (APA):

Haahr-Raunkjær, C., Meyhoff, C. S., Sørensen, H. B. D., Olsen, R. M., \& Aasvang, E. K. (2017). Technological aided assessment of the acutely ill patient - The case of postoperative complications. European Journal of Internal Medicine, 45, P41-45. https://doi.org/10.1016/j.ejim.2017.09.031

\section{General rights}

Copyright and moral rights for the publications made accessible in the public portal are retained by the authors and/or other copyright owners and it is a condition of accessing publications that users recognise and abide by the legal requirements associated with these rights.

- Users may download and print one copy of any publication from the public portal for the purpose of private study or research.

- You may not further distribute the material or use it for any profit-making activity or commercial gain

- You may freely distribute the URL identifying the publication in the public portal 


\title{
Technological aided assessment of the acutely ill patient - The case of postoperative complications
}

\author{
C. Haahr-Raunkjær ${ }^{\text {a,b, } *}$, C.S. Meyhoff ${ }^{b}$, H.B.D. Sørensen ${ }^{c}$, R.M. Olsen ${ }^{c}$, E.K. Aasvang ${ }^{a}$ \\ a Department of Anesthesiology, The Abdominal Centre, Rigshospitalet, University of Copenhagen, Copenhagen, Denmark \\ ${ }^{\mathrm{b}}$ Department of Anaesthesia and Intensive Care, Bispebjerg and Frederiksberg Hospital, University of Copenhagen, Copenhagen, Denmark \\ c Biomedical Engineering, Department of Electrical Engineering, Technical University of Denmark, Kgs. Lyngby, Denmark
}

\section{A R T I C L E I N F O}

Article history:

Received 6 September 2017

Received in revised form 22 September 2017

Accepted 24 September 2017

Available online $\mathrm{xxxx}$

\section{Keywords:}

Technological

Postoperative complications

Perioperative care

Monitoring

Continuous monitoring

\begin{abstract}
A B S T R A C T
Surgical interventions come with complications and highly reported mortality after major surgery. The mortality may be a result of delayed detection of severe complications due to lower monitoring frequency in the general wards. Several studies have shown that continuous monitoring is superior to the manually intermittent recorded monitoring in terms of detecting abnormal physiological signs. Hopefully improved observations may result in earlier detection and clinical intervention. This narrative review will describe current monitoring possibilities for postoperative patients and how it may prevent complications.

Several wireless systems are being developed for monitoring vital parameters, but many of these are not yet validated for critically ill patients. The ultimate goal with patient monitoring and detect of events is to prevent postoperative complications, death and costs in the health care system. A few studies indicate that monitoring systems detect deteriorating patients earlier than the nurses, and this was associated with less clinical instability. An important caveat of future devices is to assess their effect in relevant patient populations and not only in healthy test-subjects. Implementation of novel technologies is expensive although expected to be cost-effective if just few adverse events can be prevented. The future is here with promising devices and the possibility to give an unprecedented precise risk estimation of adverse post-surgical events. Next step is to integrate existing evidence based treatment algorithms to demonstrate the clinical efficacy of implementing the new technology.

(c) 2017 European Federation of Internal Medicine. Published by Elsevier B.V. All rights reserved.
\end{abstract}

\section{Introduction}

An estimated $>230$ million cases of major surgery are performed worldwide annually [1] with the main objective to relieve disease and discomfort and increase health. However, surgical interventions come with an inherent risk of complications not only during the intraoperative phase, but most commonly in the postoperative recovery phase. These complications are due to organ-dysfunctions in the form of impaired circulation, respiration or infections, whereof many are potentially related to an increased surgical stress response [2]. The implementation of enhanced recovery programs (ERPs) has had a significant impact on surgical outcomes across procedures. However, complications still occur in up to $15-30 \%$ of all patients undergoing major abdominal surgery. Severe morbidity (sepsis, cardiac arrest, myocardial infarction or pneumonia) is most often noted within the first 30 days postoperatively [3], with increasing risk in conjunction with increasing pre-operative co-morbidity, as evidenced by a 30\% risk in ASA III (American Society of Anaesthesiologists, physical status classification system),

* Corresponding author at: Department of Anesthesiology, The Abdominal Centre, Rigshospitalet University of Copenhagen, Blegdamsvej 9, DK-2100 Copenhagen, Denmark

E-mail address: Haahr-Raunkjaer@regionh.dk (C. Haahr-Raunkjær). and about $50 \%$ in ASA IV patients [4,5], and particularly in the acute surgical setting [6]. These numbers correspond to the reported high postoperative in-hospital mortality, 8-9\% after major upper abdominal surgery [7,8], again increased in case of co-morbidities such as chronic obstructive pulmonary disease [3]. This underlines the need for further improvements of perioperative care and especially in high risk patients (Table 1).

Part of the high morbidity and mortality may be a result of delayed detection of severe complications due to the lower monitoring frequency in the general wards compared to the Post Anesthesia Care Unit (PACU) and Intensive Care Unit (ICU). This may result in progression of the underlying pathological condition and ultimately a need for more intense treatment once the complication is discovered, which again leads to increased and persistent harm. Therefore, improved observation may result in earlier detection and subsequently the possibility to implement interventions to divert a negative trajectory and ultimately reduce morbidity and mortality [9].

Early detection to identify patients on a negative recovery path in the wards has been attempted by introducing the national Early Warning Score (EWS) [10]. The EWS is developed to direct staff attention towards patients who are in risk of deterioration, by the recording of 6 physiological parameters (respiratory rate, blood oxygen saturation, 


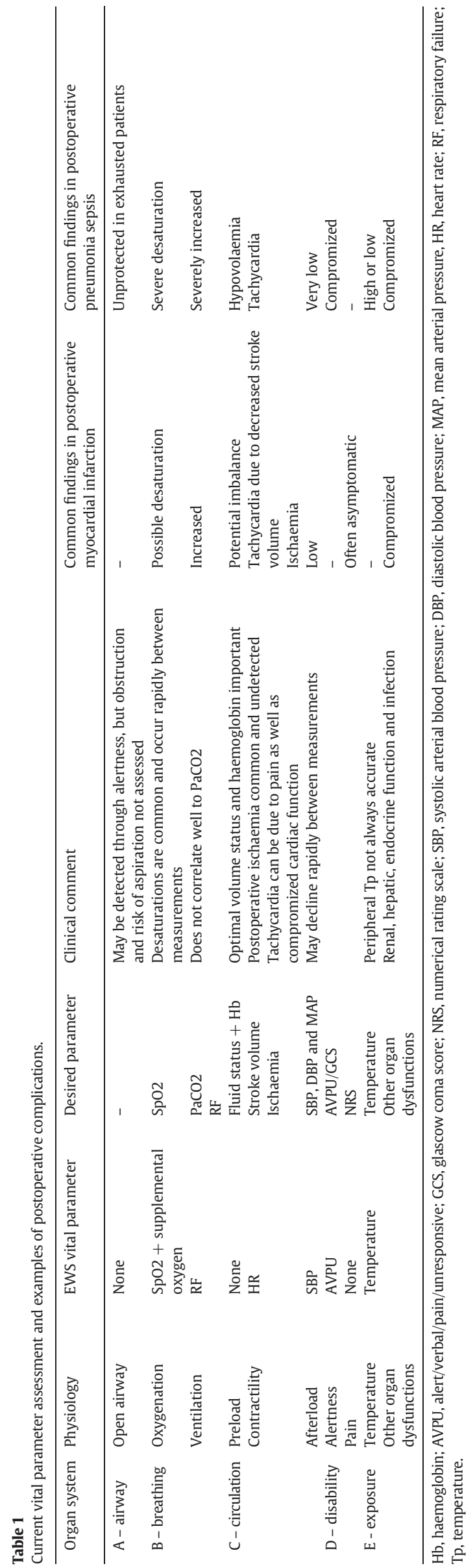

heart rate, systolic blood pressure, body-temperature and consciousness), and whether supplemental oxygen is administered. The parameters are monitored at least every $12 \mathrm{~h}$ with instructions on closer assessment depending on the severity of the combined outcome [11, $12]$.

However, saturation measurements performed during nurses rounds on postsurgical patients failed to identify up to $90 \%$ of severe desaturations, defined as values below $85 \%$, when compared to continuous automatic recordings [13]. Patients with abnormal vital signs are at higher risk of death in the hospitals compared to patients with normal vital signs. The reason for this is probably a combination of altered physiology and the lack of awareness of patients with abnormal vital signs among the nurses [14]. The authors point out a possible explanation as the lack of systematic monitoring of patients in the general wards. Conversely, the clinical effect of the EWS has been repeatedly questioned. In a 180.000 patient observational study of EWS data collected over 12 months, corresponding to > 3 million EWS entries, 10\% of all records were incomplete with values for one or more EWS variables missing, concluding that the EWS outcome was highly influenced by staff practice when data was manually recorded and entered [15]. Part of the lack of clinical effect from the EWS may be explained by the lack of adherence to EWS observation escalation protocols. Thus in cases with unplanned ICU admittance or cardia arrest, full adherence was only found in $92 \%$ of the cases [16]. The authors suggest that the lack of adherence may be due to the low staff vs patient ratio in the general wards with inability to fulfil the more intense (30 min.) observation criteria. In this setting, an automated observation with computer algorithm based alarms and suggestions for interventions may be superior to current practice even in low staff settings.

Due to the potential for assessment of preoperative risk factors and control of the surgical trauma and perioperative care, the postoperative setting provides an optimal environment for investigation of the potential and effect of optimized monitoring including detection of deterioration. Thus, this narrative review will primarily discuss the status, advantages and shortcomings of current practice of monitoring of physiologic variables. Secondly, the potential for future technological advancements such as automatic monitoring of vital parameters and adequate guidance of health personnel will conclude this narrative review.

\section{Saturation}

Low arterial oxygen saturation can result from a range of different factors such as atelectasis, alveolar hypoventilation, obesity, use of opioids and sedatives, as well as new pulmonary pathology such as pneumonia and pulmonary oedema, all of which may be present in the postoperative phase $[17,18]$ with potential for subsequent organ dysfunction due to ischemia. Pulse oximetry is nowadays a standard clinical method for assessing arterial oxygen saturation. Is it measured noninvasively by the pulse oximeter, and provides a pain-free, assessment of arterial oxygen saturation [19]. Although pulse oximetry improves the ability to detect hypoxemia and reduce episodes of ischemia in the operation room and PACU, no reduction in overall rate of postoperative complications has been found using this methodology [20], possibly because the majority of these occurs in the wards when patients are not monitored. Recent studies comparing use of intermittent recordings with continuous monitoring show that the incidence and severity of postoperative hypoxemia is underestimated [21,22]. Therefore, only $10 \%$ of all severe episodes of hypoxemia ( $\mathrm{SpO} 2<85 \%$ ) detected by continuous monitoring were detected during nurses' rounds in a prospective study with 830 patients [13]. However, the above mentioned studies fail to provide information regarding the clinical relevance of these findings, as no data on adverse outcomes (myocardial infarction, cardiac arrest, stoke etc.) were presented. The consequences of hypoxia are expected to be adverse as some data demonstrate a possible link between hypoxaemia and tachycardia, but the studies are unable to 
conclude whether tachycardia and ischemia are caused by hypoxia or vice versa [23]. An answer to this would probably help us in further understanding of the development of postoperative complications. The manually charted saturation recordings used in EWS and other scoring charts may induce false safety, as the many patients who breathe inadequately during sleep or at rest may present a normal saturation when awakened during rounds or because the recordings are only performed during normal saturation periods by chance. Moreover, often when nurses find a low saturation, they will encourage patients to breathe deeply until an improved level of saturation occurs, which afterwards is noted in the medical record [13]. Studies have demonstrated that manually measured oxygen saturation have higher recorded values than those recorded electronically [21,22]. Postoperative hypoxemia may have a significant contribution in predicting the risk of early postoperative complications. Further research in this area is required.

Postoperative hypoxemia is common and persistent in postoperative wards. However, the individual pulse oximetry threshold that will result in cardiac or cerebral injury is not predictable. Neither is the SpO2 level or the duration of desaturation that matters for development of postoperative complications - it is the overall balance between oxygen delivery and demand that results in ischemia. Thus, factors such as cardiac output, haemoglobin concentration, peripheral vasoconstriction and adaptive measures from chronic hypoxemia will affect lowest tolerable level saturation for the individual patient $[24,25]$. Oxygen therapy further comes with potential risks of hyperoxia, and liberal administrations of oxygen in an attempt to avoid desaturations is not desirable either [26]. Therefore, future monitoring systems should ideally assess multimodal factors from multiple sensors (body-networks) and patient information (e.g. healthy vs. chronic ischemic heart disease) to individualise detection and alarm thresholds. In conclusion, the current practice of saturation monitoring intervals and interpretation are not sufficient and the potential for novel technology needs investigation.

\section{Respiratory rate}

Changes in respiratory rate is an important indicator for deterioration in patients [27-29]. Both tachy- and bradypnea are considered as warning signs for potential adverse events, but with different underlying pathological mechanisms. Examples are the increased respiratory rate in pneumonia and sepsis and decreased respiratory rate with overdose of opioids. Thus, more than half of all patients experiencing a serious event, had a respiratory rate $>24 / \mathrm{min}, 24 \mathrm{~h}$ before the event in a large prospective study [30]. In another prospective study, it was found that the respiratory rate was the strongest risk predictor relating to a combination of ICU transfer, cardiac arrest and death [31], exceeding that of other vital signs, demographics and routinely collected laboratory values. Despite the clear importance of this parameter, it is the one vital sign that is often not recorded in the general wards [30,3234 ] and once recorded, there are even preferences for recording of even numbers such as a respiratory rate of 12,16 , or 20 per min.

However, potentially due to the intermittent assessment of respiratory rate in general wards, the likelihood that the abnormality in respiratory rate will be detected and thereby responded to, is low. This is evidenced by the observed discrepancy between nurses recordings and wireless monitoring, showing a low agreement in the wards [35] despite the agreement with electronical systems in high-staffed surroundings like the PACU [33]. In conclusion, the current practice of intermittent manual recording of respiratory rates does not correspond to objective monitoring with potential loss of vital information.

\section{Circulation}

Development of feasible and reliable hemodynamic monitoring is critical in postoperative patients to assess tissue perfusion and enable early evidence based interventions to improve outcomes. However, the lack of high quality studies hinders firm conclusion $[36,37]$.
Although routinely measured parameters such as pulse, blood pressure and urine output can be indicators of hypovolemia or hypoperfusion, they are not sufficient for detailed assessment of circulation and tissue oxygenation [38] to guide specific treatment protocols such as goal directed fluid therapy (GDFT). This is important as fluid over- and under treatment have been shown to increase the risk of adverse surgical outcomes, especially in critically ill patients [39]. GDFT is an individualized fluid resuscitation strategy and has been shown to improve surgical outcomes in major surgical procedures for at-risk patients [40,41], but requires a reliable dynamic hemodynamic assessment to evaluate the effect of the fluid given. Several systems for use outside the ICU and PACU are available [42] or being developed. These include non-invasive arterial pressure monitoring by finger cuff systems measuring the changes in finger arterial diameter [43], skin $\mathrm{CO}_{2}$ and bio-impedance inferring hemodynamic parameters from changes in electrical resistance. However, several of these systems require a stable physiological state or have not been tested in the unstable situation of the critically ill patient [42]. Another potential valuable parameter may be the perfusion index, assessing changes to perfusion by the relative contribution of the pulsatile vs non-pulsatile component of the routinely used pulse oximeter [44], however the clinical value in the postoperative setting has not been evaluated. Careful circulatory management are ultimately performed in an effort to detect and prevent cardiac events such as myocardial infarction caused by either a supply-demand mismatch in cardiac perfusion or a coronary thrombus. Myocardial infarction does, however, commonly present without any clinical symptoms, and is currently only possible to detect through routine measurements of cardiac enzymes such as troponin [45]. Although troponin surveillance can detect events of myocardial injury, there are no specific vital parameters to identify these events, and this is unfortunate because 30-day mortality is up to $10 \%$ among patients suffering myocardial injury after non-cardiac surgery [46], and because daily troponin surveillance will delay detection of these asymptomatic events for at least $24 \mathrm{~h}$. Nonetheless, the clinical value of this parameter in the postoperative setting has not been evaluated.

\section{Temperature}

Continuous measurement of skin temperature may reveal signs of peripheral vascular contraction, but has not yet been examined. Thus monitoring of skin temperature could detect hypovolemia, but may also be the result of pain or freezing and could be used to correct any erroneous readings from other devices - such as saturation monitors - due to non-hypovolemic peripheral contraction from pain for instance [47]. In another study, it was found that the body temperature was an important variable when predicting a combination of death, ICU transfer and cardiac arrest. The importance of temperature exceeded that of oxygen saturation and laboratory values among others [31].

\section{Other potential automated technological methods}

While parameters and devices relating to ventilation, saturation and hemodynamics are more or less implemented in clinical routine, other potential assessment methods needs mentioning as they may be part of future "body-networks", each yielding information that on its own may have predictive power, and individually or in combination with other variables may detect patients on a negative recovery trajectory. Objective assessment of pain is almost counterintuitive as pain by definition is subjective. However, pain indirectly affects other parameters by the activation of the sympathetic nervous system [48] and as such could be used to guide the need for analgesics and the efficacy of a given treatment, which may be continued or changed to analgesics with different targets (e.g. NSAIDs vs. opioids) [48]. This may allow for individualized analgesia protocols [49] and ultimately reduce the overall opioid use with well-known side effects (respiratory depression, cognitive impairment, vomiting, obstipation and pruritus). Such systems 
are still experimental [50] and should be tested against evidence based multimodal analgesic protocols to assess the effect in a clinical setting with already optimized analgesic protocols.

\section{Future: wearables and prediction}

The goal with patient monitoring is mainly to detect - and prevent postoperative complications and death. Postoperative complications increase treatment costs [51] and those who survives the complications will have a reduced long term survival [52,53]. One to five of 1000 inhospital patients in western countries sustain cardiac arrest and only $20 \%$ survive to discharge [54]. In recent years there has been increased interest in the possibilities of technology in the monitoring of patients.

Theoretically, a continuous (24/7) system that could detect patterns prior to serious events would be superior to the current EWS, as preventive interventions can be initiated before the disease becomes manifest and the damage has been done. The above postulation was examined in a large study in 2011. A continuous monitoring system did trigger an alarm in $80 \%$ of the cases with deterioration and before the patient became unstable. Furthermore in most cases, the system detected an unstable patient earlier than the traditional nurse-recording of vital parameters in most cases. The system was associated with a decreased incidence of serious instability [55]. Taenzer et al. [9] implemented a patient surveillance system in the postoperative care setting that utilized continuous pulse oximetry to detect early deterioration. The system alerted the nurse by a pager, when some defined physiologic vital parameter limits were violated. The study showed that an early deterioration of SpO2 and heart rate in the patient surveillance system, led to fewer rescue events (3.4-1-2 per 1000 patient discharges) and decreased need for escalated care (5.6-2.9 per 1000 patient days). Further research however is necessary in a larger study group, to confirm the results.

Not all studies, however, show new technology superior to best clinical practice. Non-acceptable inaccuracy and imprecision was concluded in a review comparing noninvasive arterial pressure monitoring devices with invasive gold-standard [43]. Use of more modalities could potentially give improved results.

\section{Implementation of new-technology into existing clinical practice?}

An important caveat to all of the above mentioned potential devices and futuristic implementations of technological aids, is to assess their effect in relevant patient populations and not only healthy test-subjects before implementation. Several of the reviews on the individual assessment methods $[42,49]$ show failure to investigate the usefulness in the critically ill patient populations with unstable clinical conditions. Such an example comes from the recent Ebola outbreak were a group of patients wore a body-network of sensors integrated into a simple patch, thus enabling caregivers minimal contact with high-risk (also to the health personnel) patients. The system had good correlation to standard assessed parameters although the sample size was relatively small [56].

Furthermore, implementation of novel technologies is currently expensive, although expected to quickly be cost-effective if just a few adverse events can be prevented/detected. However, the effect should be investigated in optimized treatment regimens such as ERPs [57,58], which has proven its efficacy without the novel technological aids. In a recent review, the potential for further advancement of ERPs is discussed [59]. The interesting aim of the review is not only looking at the technological potential of various devices, but their role in facilitation of adherence to ERPs - a crucial factor in the success of ERPs since the positive result on outcomes, is due to the combined effect from attention to details. However, this requires a lot from the health personnel particularly in situations with low staff-patient ratios. In this sense, automated observation, warning and guidance could facilitate ERPs adherence by decreased workload from manually collection of data, allowing staff to focus on patients on a problematic postoperative trajectory course. Although not in strictly ERPs setting such automated warning systems have already made promising results including $65 \%$ decrease in rescue events and $\sim 50 \%$ decrease in ICU transfers from continuous monitoring of saturation and heart rate alone [9].

\section{In conclusion}

The future is here with several promising wireless devices and the possibility to combine various physiological and patient characteristics [60], to give an unprecedented precise risk estimation of adverse postsurgical events. However, detection and prediction is only going half the way. The next step is to integrate existing- or develop new - evidence based treatment algorithms to demonstrate the clinical efficacy of implementing this new technology.

\section{References}

[1] Pearse RM, Moreno RP, Bauer P, Pelosi P, Metnitz P, Spies C, et al. Mortality after surgery in Europe: a 7 day cohort study. Lancet 2012;380:1059-65. https://doi.org/10. 1016/S0140-6736(12)61148-9.

[2] Steinthorsdottir KJ, Kehlet H, Aasvang EK. The surgical stress response and the potential role of preoperative glucocorticoids on post-anesthesia care unit recovery. Minerva Anestesiol 2017. https://doi.org/10.23736/S0375-9393.17.11878-X.

[3] Fields AC, Divino CM. Surgical outcomes in patients with chronic obstructive pulmonary disease undergoing abdominal operations: an analysis of 331,425 patients. Surgery 2016;159:1210-6. https://doi.org/10.1016/j.surg.2015.11.007.

[4] International Surgical Outcomes Study group TISOS. Global patient outcomes after elective surgery: prospective cohort study in 27 low-, middle- and high-income countries. Br J Anaesth 2016;117:601-9. https://doi.org/10.1093/bja/aew316.

[5] Hansen MS, Petersen EE, Dahl JB, Wetterslev J. Post-operative serious adverse events in a mixed surgical population - a retrospective register study. Acta Anaesthesiol Scand 2016;60:1209-21. https://doi.org/10.1111/aas.12762.

[6] Botto F, Alonso-Coello P, Chan MTV, Villar JC, Xavier D, Srinathan S, et al. Myocardial injury after noncardiac surgery. Anesthesiology 2014;120:564-78. https://doi.org/ 10.1097/ALN.0000000000000113.

[7] Jensen LS, Bendixen A, Kehlet H. Organisation and early outcomes of major upper gastrointestinal cancer surgery in Denmark 1996-2004. Scand J Surg 2007;96: 41-5. https://doi.org/10.1177/145749690709600108.

[8] Boehm O, Baumgarten G, Hoeft A. Epidemiology of the high-risk population: perioperative risk and mortality after surgery. Curr Opin Crit Care 2015;21:322-7. https:// doi.org/10.1097/MCC.0000000000000221.

[9] Taenzer AH, Pyke JB, McGrath SP, Blike GT. Impact of pulse oximetry surveillance on rescue events and intensive care unit transfers. Anesthesiology 2010;112:282-7. https://doi.org/10.1097/ALN.0b013e3181ca7a9b.

[10] The Royal College of Physicians (RCP). National Early Warning Score (NEWS) | RCP London n.d. https://www.rcplondon.ac.uk/projects/outputs/national-earlywarning-score-news (accessed August 14, 2017).

[11] Smith GB, Prytherch DR, Meredith P, Schmidt PE, Featherstone PI. The ability of the National Early Warning Score (NEWS) to discriminate patients at risk of early cardiac arrest, unanticipated intensive care unit admission, and death. Resuscitation 2013;84:465-70. https://doi.org/10.1016/j.resuscitation.2012.12.016.

[12] Jensen CS, Aagaard H, Olesen HV, Kirkegaard H. A multicentre, randomised intervention study of the Paediatric Early Warning Score: study protocol for a randomised controlled trial. Trials 2017;18:267. https://doi.org/10.1186/s13063-017-2011-7.

[13] Sun Z, Sessler DI, Dalton JE, Devereaux P, Shahinyan A, Naylor AJ, et al. Postoperative hypoxemia is common and persistent: a prospective blinded observational study. Anesth Analg 2015;121:709-15. https://doi.org/10.1213/ANE.0000000000000836.

[14] Fuhrmann L, Lippert A, Perner A, Østergaard D. Incidence, staff awareness and mortality of patients at risk on general wards. Resuscitation 2008;77:325-30. https:// doi.org/10.1016/j.resuscitation.2008.01.009.

[15] Pedersen NE, Rasmussen LS, Petersen JA, Gerds TA, Østergaard D, Lippert A. A critical assessment of early warning score records in 168,000 patients. J Clin Monit Comput 2017:1-8. https://doi.org/10.1007/s10877-017-0003-5.

[16] Petersen JA, Mackel R, Antonsen K, Rasmussen LS. Serious adverse events in a hospital using early warning score - what went wrong? Resuscitation 2014;85: 1699-703. https://doi.org/10.1016/j.resuscitation.2014.08.037.

[17] Karcz M, Papadakos PJ. Respiratory complications in the postanesthesia care unit: a review of pathophysiological mechanisms. Can J Respir Ther CJRT = Rev Can La Ther Respir RCTR 2013;49:21-9.

[18] Oderda GM, Gan TJ, Johnson BH, Robinson SB. Effect of opioid-related adverse events on outcomes in selected surgical patients. J Pain Palliat Care Pharmacother 2013;27: 62-70. https://doi.org/10.3109/15360288.2012.751956.

[19] Collins J-A, Rudenski A, Gibson J, Howard L, O'Driscoll R. Relating oxygen partial pressure, saturation and content: the haemoglobin-oxygen dissociation curve. Breathe (Sheff) 2015;11:194-201. https://doi.org/10.1183/20734735.001415.

[20] Moller JT, Johannessen NW, Espersen K, Ravlo O, Pedersen BD, Jensen PF, et al. Randomized evaluation of pulse oximetry in 20,802 patients: II. Perioperative events and postoperative complications. Anesthesiology 1993;78:445-53.

[21] Ramachandran SK, Thompson A, Pandit JJ, Devine S, Shanks AM. Retrospective observational evaluation of postoperative oxygen saturation levels and associated 
postoperative respiratory complications and hospital resource utilization. PLoS One 2017;12:e0175408. https://doi.org/10.1371/journal.pone.0175408.

[22] Taenzer AH, Pyke J, Herrick MD, Dodds TM, McGrath SP. A comparison of oxygen saturation data in inpatients with low oxygen saturation using automated continuous monitoring and intermittent manual data charting. Anesth Analg 2014;118: 326-31. https://doi.org/10.1213/ANE.0000000000000049.

[23] Gogenur I, Rosenberg-Adamsen S, Lie C, Carstensen M, Rasmussen V, Rosenberg J. Relationship between nocturnal hypoxaemia, tachycardia and myocardial ischaemia after major abdominal surgery. Br J Anaesth 2004;93:333-8. https://doi.org/10. 1093/bja/aeh208.

[24] Bendixen HH, Hedley-Whyte J, Laver MB. Impaired oxygenation in surgical patients during general anesthesia with controlled ventilation. A concept of telectasis. N Eng J Med 1963;269:991-6. https://doi.org/10.1056/NEJM196311072691901.

[25] Kumar H, Choi D-K. Hypoxia inducible factor pathway and physiological adaptation: a cell survival pathway? Mediators Inflamm 2015;2015:584758. https://doi.org/10. $1155 / 2015 / 584758$

[26] Meyhoff CS, Staehr AK, Rasmussen LS. Rational use of oxygen in medical disease and anesthesia. Curr Opin Anaesthesiol 2012;25:363-70. https://doi.org/10.1097/ACO. 0b013e328352b402.

[27] Van Loon K, Breteler MJM, Van Wolfwinkel L, Rheineck Leyssius AT, Kossen S, Kalkman CJ, et al. Wireless non-invasive continuous respiratory monitoring with FMCW radar: a clinical validation study. J Clin Monit Comput 2016;30:797-805. https://doi.org/10.1007/s10877-015-9777-5.

[28] Fie JF, Helms CM. Respiratory rate predicts cardiopulmonary arrest for internal medicine inpatients. J Gen Intern Med 1993;8:354-60.

[29] Churpek MM, Yuen TC, Huber MT, Park SY, Hall JB, Edelson DP. Predicting cardiac arrest on the wards: a nested case-control study. Chest 2012;141:1170-6. https://doi. org/10.1378/chest.11-1301.

[30] Cretikos M, Chen J, Hillman K, Bellomo R, Finfer S, Flabouris A, et al. The objective medical emergency team activation criteria: a case-control study. Resuscitation 2007;73:62-72. https://doi.org/10.1016/j.resuscitation.2006.08.020.

[31] Churpek MM, Yuen TC, Winslow C, Meltzer DO, Kattan MW, Edelson DP. Multicenter comparison of machine learning methods and conventional regression for predicting clinical deterioration on the wards. Crit Care Med 2016;44:368-74. https://doi.org/10.1097/CCM.0000000000001571.

[32] Hogan J, Hogan J. Why don't nurses monitor the respiratory rates of patients? $\mathrm{Br}$ ] Nurs 2006;15:489-92. https://doi.org/10.12968/bjon.2006.15.9.21087.

[33] Lee PJ. Clinical evaluation of a novel respiratory rate monitor. J Clin Monit Comput 2016;30:175-83. https://doi.org/10.1007/s10877-015-9697-4.

[34] McBride J, Knight D, Piper J, Smith GB. Long-term effect of introducing an early warning score on respiratory rate charting on general wards. Resuscitation 2005; 65:41-4. https://doi.org/10.1016/j.resuscitation.2004.10.015.

[35] Granholm A, Pedersen NE, Lippert A, Petersen LF, Rasmussen LS. Respiratory rates measured by a standardised clinical approach, ward staff, and a wireless device. Acta Anaesthesiol Scand 2016;60:1444-52. https://doi.org/10.1111/aas.12784.

[36] Cronhjort M, Wall O, Nyberg E, Zeng R, Svensen C, Mårtensson J, et al. Impact of hemodynamic goal-directed resuscitation on mortality in adult critically ill patients: systematic review and meta-analysis. J Clin Monit Comput 2017:1-12. https://doi. org/10.1007/s10877-017-0032-0.

37] Saugel B, Michard F, Scheeren TWL. Goal-directed therapy: hit early and personalize! J Clin Monit Comput 2017:1-3. https://doi.org/10.1007/s10877-017-0043-x.

[38] Molnar Z, Szabo Z, Nemeth M. Multimodal individualized concept of hemodynamic monitoring. Curr Opin Anaesthesiol 2017;30:171-7. https://doi.org/10.1097/ACO. 0000000000000440

[39] Thiele RH, Raghunathan K, Brudney CS, Lobo DN, Martin D, Senagore A, et al. American Society for Enhanced Recovery (ASER) and Perioperative Quality Initiative (POQI) joint consensus statement on perioperative fluid management within an enhanced recovery pathway for colorectal surgery. Perioper Med (London, England) 2016;5:24. https://doi.org/10.1186/s13741-016-0049-9.

[40] Pearse RM, Harrison DA, MacDonald N, Gillies MA, Blunt M, Ackland G, et al. Effect of a perioperative, cardiac output-guided hemodynamic therapy algorithm on outcomes following major gastrointestinal surgery. JAMA 2014;311:2181. https://doi. org/10.1001/jama.2014.5305.
[41] Osawa EA, Rhodes A, Landoni G, Galas FRBG, Fukushima JT, Park CHL, et al. Effect of perioperative goal-directed hemodynamic resuscitation therapy on outcomes following cardiac surgery. Crit Care Med 2015;1. https://doi.org/10.1097/CCM. 0000000000001479

[42] Bendjelid K, Rex S, Scheeren T, Saugel B. Journal of Clinical Monitoring and Computing 2015 end of year summary: cardiovascular and hemodynamic monitoring. J Clin Monit Comput 2016;30:129-39. https://doi.org/10.1007/s10877-016-9838-4.

[43] Kim S-H, Lilot M, Sidhu KS, Rinehart J, Yu Z, Canales C, et al. Accuracy and precision of continuous noninvasive arterial pressure monitoring compared with invasive arterial pressure. Anesthesiology 2014;120:1080-97. https://doi.org/10.1097/ALN. 0000000000000226

[44] Lima A, Bakker J. Noninvasive monitoring of peripheral perfusion. Intensive Care Med 2005;31:1316-26. https://doi.org/10.1007//00134-005-2790-2.

[45] Sessler DI, Devereaux PJ. Perioperative troponin screening. Anesth Analg 2016;123: 359-60. https://doi.org/10.1213/ANE.0000000000001450.

[46] Devereaux PJ, Sessler DI. Cardiac complications in patients undergoing major noncardiac surgery. N Engl J Med 2015;373:2258-69. https://doi.org/10.1056/ NEJMra1502824

[47] Lima A, Bakker J. Clinical assessment of peripheral circulation. Curr Opin Crit Care 2015;21:226-31. https://doi.org/10.1097/MCC.0000000000000194.

[48] Koenig J, Jarczok MN, Ellis RJ, Hillecke TK, Thayer JF. Heart rate variability and experimentally induced pain in healthy adults: a systematic review. Eur J Pain 2014;18: 301-14. https://doi.org/10.1002/j.1532-2149.2013.00379.x.

[49] Gruenewald M, Ilies C. Monitoring the nociception-anti-nociception balance. Best Pract Res Clin Anaesthesiol 2013;27:235-47. https://doi.org/10.1016/j.bpa.2013.06. 007.

[50] Cowen R, Stasiowska MK, Laycock H, Bantel C. Assessing pain objectively: the use of physiological markers. Anaesthesia 2015;70:828-47. https://doi.org/10.1111/anae. 13018.

[51] Scally CP, Thumma JR, Birkmeyer JD, Dimick JB. Impact of surgical quality improvement on payments in Medicare patients. Ann Surg 2015;262:249-52. https://doi. org/10.1097/SLA.0000000000001069.

[52] Khuri SF, Henderson WG, DePalma RG, Mosca C, Healey NA, Kumbhani DJ, et al. Determinants of long-term survival after major surgery and the adverse effect of postoperative complications. Ann Surg 2005;242:326-41-3. https://doi.org/10.1097/01. sla.0000179621.33268.83.

[53] Pearse RM, Holt PJE, Grocott MPW. Managing perioperative risk in patients undergoing elective non-cardiac surgery. BMJ 2011;343 d5759-d5759. https://doi.org/10. 1136/bmj.d5759.

[54] Sandroni C, Nolan J, Cavallaro F, Antonelli M, Sandroni C, Cavallaro F, et al. In-hospital cardiac arrest: incidence, prognosis and possible measures to improve survival. Intensive Care Med 2007;33:237-45. https://doi.org/10.1007/s00134-006-0326-z.

[55] Hravnak M. Devita MA, Clontz A, Edwards L Valenta C, Pinsky MR. Cardiorespiratory instability before and after implementing an integrated monitoring system. Crit Care Med 2011;39:65-72. https://doi.org/10.1097/CCM.0b013e3181fb7b1c.

[56] Steinhubl SR, Feye D, Levine AC, Conkright C, Wegerich SW, Conkright G. Validation of a portable, deployable system for continuous vital sign monitoring using a multiparametric wearable sensor and personalised analytics in an Ebola treatment centre. BMJ Glob Heal 2016;1:e000070. https://doi.org/10.1136/bmjgh-2016000070.

[57] Kehlet H. Stress free anaesthesia and surgery. Acta Anaesthesiol Scand 1979;23: 503-4.

[58] Kehlet H. Multimodal approach to control postoperative pathophysiology and rehabilitation. Br J Anaesth 1997;78:606-17. https://doi.org/10.1093/bja/78.5.606.

[59] Michard F, Gan TJ, Kehlet H. Digital innovations and emerging technologies for enhanced recovery programmes. BJA Br J Anaesth 2017;119:31-9. https://doi.org/10. $1093 /$ bja/aex140.

[60] Kaufman M, Bebee B, Bailey J, Robbins R, Hart GK, Bellomo R. Laboratory tests to identify patients at risk of early major adverse events: a prospective pilot study. Intern Med J 2014;44:1005-12. https://doi.org/10.1111/imj.12509. 